\title{
Recovery of cognitive dysfunction in a case of delayed encephalopathy of carbon monoxide poisoning after treatment with donepezil hydrochloride
}

\author{
Pin Wang, Tao Zeng ${ }^{1}$, Zhao-fu Chi \\ Department of Neurology, QiLu Hospital of Shandong University, 44 West Wenhua road, Jinan, Shandong 250012, ${ }^{1}$ Departments of \\ Institute of Toxicology, Shandong University, 44 West Wenhua Road, Jinan, Shandong - 250 012, China
}

\author{
Address for correspondence: \\ Dr. Zhao-fu Chi, \\ Department of Neurology, QiLu \\ Hospital of Shandong University, \\ 44 West Wenhua Road, Jinan, \\ Shandong - 250012, P.R. China. \\ E-mail: chizf1949@yahoo.cn
}

DOI: $10.4103 / 0028-3886.55596$

\begin{abstract}
Delayed encephalopathy following carbon monoxide poisoning is a serious complication. Here, we report a patient with delayed encephalopathy who suffered from cognitive disorders and urinary incontinence after a temporal normal period of 15 days after acute intoxication, and his cognitive function recovered gradually following donepezil hydrochloride treatment. Now, he can undertake slight farming work.
\end{abstract}

Key words: Carbon monoxide, cognitive dysfunction, delayed encephalopathy, donepezil hydrochloride

\section{Introduction}

Carbon monoxide ( $\mathrm{CO}$ ) poisoning is the leading cause of lethal poisonings in the world. A number of recent reports indicate that it is likely misdiagnosed as a cause of headache, fatigue, dizziness, and other neurological complications. The underlying mechanisms of $\mathrm{CO}$ toxicity, especially delayed toxicity, are poorly understood to date. Neurological and psychiatric symptoms including speech disorders, delirium, epileptic seizures, Parkinsonism, agnosia, ataxia, apraxia, and amnesic disturbances may appear. ${ }^{[1]}$ In $40 \%$ of the cases, more permanent changes such as moderate amnesic disorders and personality changes were reported..$^{[2]}$ Terajima reported that white matter demyelination, aerobic metabolism inhibition, and cytotoxic edema persisted for at least three months even after starting the hyperbaric oxygenation therapy. ${ }^{[3]} \mathrm{A}$ biphasic pattern exhibits in some patients. Patients may fully recover after antitoxic treatment. However, neurological and/or psychiatric symptoms might reappear following a short recovery period. Its recurrence rate is about $0.06-11.8 \%{ }^{[4]}$ The exact pathogenic mechanism remains unclear. ${ }^{[5]}$

\section{Case Report}

A 60-year-old man was found unconscious on a winter morning in his room where there were remnants of burned-out charcoal briquettes. On arrival to our emergency department, he was unconscious with nausea, vomiting, high fever, and urinary incontinence for about three hours. He had no past history or family history of hypertension, diabetes, cardiac disease, liver disease, or neurological/psychiatric disorders. The concentration of $\mathrm{CO}$ hemoglobin $(\mathrm{COHb})$ was $11.2 \%$, and thus he was diagnosed as a case of acute $\mathrm{CO}$ poisoning based on both his circumstantial evidence and laboratory results.

The patient came around in the afternoon of the same day after receiving hyperbaric oxygen (HBO) treatment. Abnormal findings were observed in the blood (WBC: $15.8 \times 10^{9}$; Gran\%: 85.8\%), while blood sedimentation speed, urine assessments, thyroid function tests, vitamin B12, folic acid levels, and EEG were all normal. His temperature recurred to normal standard level after one day treatment. After $\mathrm{HBO}$ and antitoxic treatment for 10 days, the patient was discharged with 
a full recovery and remained free of symptoms for 15 days. In January 2008, he started to experience progressive forgetfulness, depression, disordered speech, urinary incontinence, hemiparesis, and presented to our hospital with the diagnosis of the delayed neuropathy. Though he was administered $\mathrm{HBO}$ treatment and antitoxic treatment, including drugs for decreasing the cerebral edema and clearing away free radicals, for another 10 days, little therapeutic effect was seen through these methods. Hence, we selected donepezil hydrochloride (donepezil $\mathrm{HCl}$ ) which is a drug thought to discourage the breakdown of acetylcholine, a neurotransmitter in the brain that is important to how memory functions. Donepezil $\mathrm{HCl}$ has been reported to have benefits for people with mild to moderate memory dysfunction.

No pathological findings were displayed in ordinary tests, but his mini mental state examination (MMSE) score was only $9 / 30$ and Hamilton depression rating scale (HAM-D) score was 10. During hospitalization, the initial dose of donepezil Hcl was $5 \mathrm{mg}$ /day for oral use, and gradually increased to $10 \mathrm{mg} /$ day for about two months. Two months later, the patient's memory deficiency and cognitive impairment gradually recovered, and the MMSE and HAM-D scores reached to 25/30 and 14 [Table 1], respectively. Then the patient was discharged and was followed up as an outpatient. During the follow up, donepezil Hcl dosage was decreased to $5 \mathrm{mg}$ /day and sustained. His symptoms have remained stable up to now.

In delayed encephalopathy, more patients suffer from functional deficiencies, including abnormal personality and cognitive impairment. ${ }^{[6]}$ The latent period of late neuropathy was about 2-40 days after the acute phase in one study. ${ }^{[7]} \mathrm{HBO}$ treatment for acute $\mathrm{CO}$ poisoning has been reported to decrease the incidence of delayed neuropsychiatric sequelae ${ }^{[8]}$ which failed to provide the neuroprotective effect as compared with the normobaric oxygen therapy in a recent animal study ${ }^{[9]}$ It seems that no specific treatment is required for delayed encephalopathy. Since cerebral cortex, basal ganglia, and hippocampus are very sensitive to hypoxia, the cerebral hypoxia caused by $\mathrm{CO}$ poisoning can only account for the syndromes of acute phase. Therefore, immunological responses or apoptosis may be involved in the development of the delayed neurological sequelae. ${ }^{[10]}$

Donepezil Hcl appeared to be effective in our case. Recently, the AChE-inhibitor donepezil was found to have neuroprotective effects. However, the protective mechanisms of donepezil are yet to be clearly identified.
Table 1: Longitudinal assessment of neurological-related functions

\begin{tabular}{lccc}
\hline & $\begin{array}{c}\text { Acute stage } \\
(10 \text { days } \\
\text { after CO } \\
\text { poisoning) }\end{array}$ & $\begin{array}{c}25 \text { days } \\
\text { following } \\
\text { CO } \\
\text { poisoning }\end{array}$ & $\begin{array}{c}85 \text { days } \\
\text { following } \\
\text { CO } \\
\text { poisoning }\end{array}$ \\
\hline MMSE & 30 & $9 / 30$ & $25 / 30$ \\
HAM-D & 35 & 10 & 14 \\
EEG & Normal & Normal & Normal \\
Blood sedimentation speed & Normal & Normal & Normal \\
Vitamin B12 (pmol/L) & 516 & 543 & 521 \\
Folic acid levels $(\mathrm{ng} / \mathrm{ml})$ & 18.86 & 22.76 & 19.96 \\
\hline
\end{tabular}

As Min-Young Noh had reported, ${ }^{[11]}$ the neuroprotective effects of donepezil may be related to be against amyloid- $\beta 1-42$ (A $\beta 42)$ induced neurotoxicity in rat cortical neurons. Further studies are warranted to confirm its effectiveness in the treatment of this serious complication of $\mathrm{CO}$ intoxication.

\section{References}

1. Choi IS. Carbon monoxide poisoning: Systemic manifestations and complications. J Korean Med Sci 2001;16:253-61.

2. Lugaresi A, Montagna P, Morreale A, Gallassi R. 'Psychic akinesia following carbon monoxide poisoning. Eur Neurol 1990;30:167-9.

3. Terajima K, Igarashi H, Hirose M, Matsuzawa H, Nishizawa M, Nakada T. Serial assessments of delayed encephalopathy after carbon monoxide poisoning using magnetic resonance spectroscopy and diffusion tensor imaging on 3.0T system. Eur Neurol 2008;59:55-61.

4. Choi IS. Delayed neurologic sequelae in carbon monoxide intoxication. Arch Neurol 1983;40:433-5.

5. Kim JH, Chang KH, Song IC, Kim KH, Kwon BJ, Kim HC, et al. Delayed encephalopathy of acute carbon monoxide intoxication: Diffusivity of cerebral white matter lesions. AJNR Am J Neuroradiol 2003;24:1592-7.

6. Gürlek Yüksel E, Taskin EO, Yilmaz Ovali G, Karaçam M, Esen Danaci A. [Case report: Kleptomania and other psychiatric symptoms after carbon monoxide intoxication] Turk Psikiyatri Derg 2007;18:80-6.

7. Deckel AW. Carbon monoxide poisoning and frontal lobe pathology: Two case reports and a discussion of the literature. Brain Inj 1994;8:345-56.

8. Thom SR, Taber RL, Mendiguren II, Clark JM, Hardy KR, Fisher AB. Delayed neuropsychologic sequelae after carbon monoxide poisoning: Prevention by treatment with hyperbaricoxygen. Ann Emerg Med 1995;25:474-80.

9. Gilmer B, Kilkenny J, Tomaszewski C, Watts JA. Hyperbaric oxygen dose not prevent neurologic sequelae after carbon monoxide poisoning. Acad Emerg Med 2002;9:1-8.

10. Thom SR, Bhopale VM, Fisher D, Zhang J, Gimotty P. Delayed neuropathology after carbon monoxide poisoning is immune-mediated. Proc Natl Acad Sci U S A 2004;101:13660-5.

11. Noh MY, Koh SH, Kim Y, Kim HY, Cho GW, Kim SH. Neuroprotective effects of donepezil through inhibition of GSK-3 activity in amyloid-beta-induced neuronal cell death. J Neurochem 2009;108:1116-25

Accepted on 15-03-2009

Source of Support: Nil, Conflict of Interest: None declared. 